\title{
Celastrus orbiculatus extracts induce cell cycle arrest and apoptosis in human esophageal squamous carcinoma ECA-109 cells in vitro via the PI3K/AKT/mTOR signaling pathway
}

\author{
FENG JIN $^{1}$, GUANG ZHU ${ }^{1}$, DAN LI ${ }^{1}$, TENGYANG NI ${ }^{1}$, XIAOJUN DAI ${ }^{1,2}$, HAIBO WANG $^{1}$, \\ JUN FENG $^{1}$, YAYUN QIAN ${ }^{1}$, LIN YANG ${ }^{1}$, SHIYU GUO ${ }^{3}$, TADASHI HISAMITSU ${ }^{3}$ and YANQING LIU ${ }^{1}$ \\ ${ }^{1}$ Institute of Traditional Chinese Medicine and Western Medicine, School of Medicine, \\ Yangzhou University; ${ }^{2}$ Department of Oncology, Yangzhou Hospital of Traditional Chinese Medicine, Yangzhou, \\ Jiangsu 225009, P.R. China; ${ }^{3}$ Department of Physiology, Showa University, Tokyo 142-8555, Japan
}

Received April 12, 2016; Accepted July 11, 2017

DOI: $10.3892 / \mathrm{ol} .2017 .7459$

\begin{abstract}
Recently, Celastrus orbiculatus ethyl acetate extracts (COE) have been investigated for their anticancer effects on digestive tract tumors. However, the therapeutic effects of COE on esophageal squamous carcinoma cells (ESCC) have not been investigated. In the present study, the effects of COE on the cell cycle and apoptosis of ESCCs were assessed in vitro, and it was revealed that $\mathrm{COE}$ treatment triggered $\mathrm{G}_{0} / \mathrm{G}_{1}$ cell cycle arrest, and induced DNA damage and apoptosis in a dose-dependent manner in ESCC. Activation of the phosphatidylinositol 3-kinase/protein kinase-B/mechanistic target of rapamycin (mTOR) pathway was also suppressed by COE. Additionally, the combined treatment with $\mathrm{COE}$ and rapamycin (an mTOR inhibitor) acted synergistically in ECA-109 cells compared with the treatment with COE or rapamycin alone. These findings extend the understanding of the action of $\mathrm{COE}$ and suggest that $\mathrm{COE}$ has potential as a treatment option for ESCC as a single treatment or in combination.
\end{abstract}

\section{Introduction}

Esophageal cancer is the eighth most common cancer type and the sixth-leading cause of cancer-associated mortality globally (1). Esophageal squamous cell carcinoma (ESCC) is the main subtype of esophageal cancer, comprising 70\% of esophageal cancer occurrences, with incidence rates

Correspondence to: Professor Yanqing Liu, Institute of Traditional Chinese Medicine and Western Medicine, School of Medicine, Yangzhou University, 11 Huaihai Road, Yangzhou, Jiangsu 225009, P.R. China

E-mail: liuyq@yzu.edu.cn

Key words: Celastrus orbiculatus, esophageal squamous carcinoma cells, cell cycle, apoptosis, phosphoinositide-3 kinase/protein kinase $\mathrm{B} /$ mechanistic target of rapamycin signaling pathway varying widely with geographic location (2-4). The World Health Organization estimated that $~ 50 \%$ of total ESCC cases occurred in China, while there were 197,472 occurrences of ESCC-associated mortality globally in 2012 (5). In China, the majority of patients with ESCC are diagnosed with advanced-stage disease and the 5-year survival rate is $4.4 \%$ (5). At present, the treatment of this disease is relatively ineffective, owing to recurrence, metastasis and the development of resistance to radiation, and chemotherapy resistance $(6,7)$. Therefore, the identification of novel therapeutic agents for cancer with high selectivity and low toxicity may represent a step forward in treatment.

The phosphatidylinositol 3-kinase (PI3K)/protein kinase B (AKT)/mechanistic target of rapamycin (mTOR) signaling pathway is involved in multiple essential processes, including cellular metabolism, proliferation, cell cycle regulation, cytoskeletal reorganization and tumor development $(8,9)$. In cancer cells, this pathway has a marked effect on the regulation of cell growth and survival, ultimately conferring a competitive growth advantage, inducing entry into the cell cycle, and enabling metastatic competence, angiogenesis and resistance to therapy $(10,11)$. PI3K is activated by the binding of a growth factor or ligand to its cognate growth factor receptor tyrosine kinase, which leads to the phosphorylation and activation of Akt, a serine/threonine kinase. Phosphorylation of AKT stimulates protein synthesis and cell growth by activating mTOR (12).

Celastrus orbiculatus (Celastraceae) is a traditional medicine used to treat numerous symptoms and diseases, including ache, arthritis and other inflammatory diseases (13). Previous studies indicate that Celastrus orbiculatus extracts (COE) exhibit multiple biological properties, including antitumor, anti-inflammatory, analgesic, antifertility, antibacterial and antiviral properties $(14,15)$. COE have been identified to exhibit anticancer effects. Several studies have demonstrated that $\mathrm{COE}$ can interfere with growth of stomach, colon and liver cancer cells through the inhibition of proliferation, angiogenesis, invasion and metastasis, and the induction of apoptosis in vitro and in vivo (16-24). However, the therapeutic effects of COE on ESCC have not been investigated. The present study 
aimed to elucidate the anticancer effects of $\mathrm{COE}$, and whether they were mediated via growth inhibition, cell cycle arrest, apoptosis and DNA damage in ESCC; it also aimed to identify the possible mechanism underlying these effects by inhibiting the PI3K/AKT/mTOR signaling pathway.

\section{Materials and methods}

Preparation of COE. Celastrus orbiculatus plants (production batch no. 070510) were purchased from Guangzhou Zhixin Pharmaceutical Co., Ltd. (Guangzhou, China) in 2007 and extracted at the Department of Chinese Materia Medica Analysis, China Pharmaceutical University (Nanjing, China) as described previously (22). The chemical constituents of the stems of COE were investigated and compounds were isolated as described previously $(24,25)$. The resultant COE micropowder was dissolved in DMSO (Sigma-Aldrich; Merck $\mathrm{KGaA}$, Darmstadt, Germany) and diluted to produce a range of different concentrations prior to use. The final concentration of DMSO in the cell culture did not exceed $0.1 \%$.

Cell culture. The human esophageal squamous carcinoma ECA-109 cell line was obtained from the Cell Bank of Chinese Academy of Sciences, Shanghai Institute of Cell Biology (Shanghai, China). Cells were cultured in RPMI-1640 containing $10 \%$ fetal bovine serum (both Gibco; Thermo Fisher Scientific, Waltham, MA, USA) in a $5 \% \mathrm{CO}_{2}$ incubator at $37^{\circ} \mathrm{C}$ in a humidified atmosphere.

Cell viability assay. A total of $2.0 \times 10^{3}$ ECA-109 cells/well were seeded into 96 -well plates and incubated at $37^{\circ} \mathrm{C}$ in a $5 \% \mathrm{CO}_{2}$ incubator for $24 \mathrm{~h}$. Next, cells were treated with different concentrations of COE $(320,160,80,40$ or $20 \mathrm{mg} / \mathrm{l})$ for 24,48 or $72 \mathrm{~h}$. A negative control group consisting of untreated cells was also included. The plate was subjected to treatment with $5 \mathrm{mg} / \mathrm{ml}$ MTT (Sigma-Aldrich, Merck KGaA) dissolved in sterile PBS in dark for $4 \mathrm{~h}$ in a $5 \% \mathrm{CO}_{2}$ incubator at $37^{\circ} \mathrm{C}$, and the optical density (OD) value was measured at $490 \mathrm{~nm}$. The tests were independently performed $\geq 3$ times. The cell viability rate was calculated as follows: (OD value of each concentration group/OD value of negative control group) $\mathrm{x} 100$.

Cell cycle analysis. A total of $1 \times 10^{6}$ ECA-109 cells treated with $0,20,40$ or $80 \mathrm{mg} / \mathrm{l} \mathrm{COE}$ for $24 \mathrm{~h}$ were harvested, and then fixed in $70 \%$ ethanol at $4^{\circ} \mathrm{C}$ for $2 \mathrm{~h}$. After $24 \mathrm{~h}$, the cells were washed twice with ice-cold PBS, stained with enough neat propidium iodide (PI)/RNase Staining Solution (Cell Signaling Technology, Inc., Danvers, MA, USA) at $25^{\circ} \mathrm{C}$ for $15 \mathrm{~min}$ in the dark. The measurements were performed using a FACSCaliber flow cytometer and Cell Quest Pro software version 349226 (BD Biosciences, Franklin Lakes, NJ, USA). The data were analyzed using FlowJo 7.6 software (Tree Star, Inc., Ashland, OR, USA). The tests were performed $\geq 3$ independent times.

Cell apoptosis assay. A total volume of $1 \times 10^{6}$ ECA-109 cells were treated with $0,20,40$ or $80 \mathrm{mg} / \mathrm{l} \mathrm{COE}$ for $24 \mathrm{~h}$, and the harvested cells were washed twice with ice-cold PBS. Apoptotic cells were identified using the Annexin V-Fluorescein
Isothiocyanate (FITC)/PI Apoptosis Detection kit (Nanjing KeyGen Biotech Co., Ltd., Nanjing, China). After centrifugation at $100 \mathrm{x}$ g for $5 \mathrm{~min}$ at $4^{\circ} \mathrm{C}, 290 \mu \mathrm{l}$ of $1 \mathrm{X}$ binding buffer, $5 \mu \mathrm{l}$ of Annexin V-FITC and $5 \mu \mathrm{l}$ of PI were added to the pellet, and incubated at room temperature $\left(25^{\circ} \mathrm{C}\right)$ for $15 \mathrm{~min}$ in the dark. Next, $200 \mu \mathrm{l}$ of $1 \mathrm{X}$ binding buffer was added prior to measurement. The data were measured and analyzed with the same machine and software as the cell cycle assay. The cell apoptosis assay was performed with 3 independent experiments.

Evaluation of mitochondrial membrane depolarization. The Mitochondrial Membrane Potential Detection kit JC-1 (Beyotime Institute of Biotechnology, Hangzhou, China) was used to measure the changes of the mitochondria membrane potential. Following treatment with $0,20,40$ or $80 \mathrm{mg} / \mathrm{l} \mathrm{COE}$ for $24 \mathrm{~h}$, the cells were incubated with $1 \mathrm{ml} \mathrm{JC}-1$ working solution for $20 \mathrm{~min}$ at $37^{\circ} \mathrm{C}$ in the dark, and then washed twice with JC-1 buffer. The results were observed using a fluorescence microscope at magnification, $\mathrm{x} 100$.

Transmission electron microscopy. ECA-109 cells in the logarithmic growth phase were incubated with $0,20,40$ or $80 \mathrm{mg} / 1$ $\mathrm{COE}$ for $24 \mathrm{~h}$. Cells were harvested and the supernatant was discarded. Cells were then washed twice with PBS, and $2.5 \%$ glutaraldehyde was added over $2 \mathrm{~h}$ at $4^{\circ} \mathrm{C}$. Following a wash with $0.1 \mathrm{mM}$ PBS, the cells were fixed in $1 \%$ osmium teroxide for $2 \mathrm{~h}$ at $4^{\circ} \mathrm{C}$, and then washed, dehydrated in a graded alcohol series and acetone. Cells were embedded in different proportions of Epon 812 resin, sectioned at $50 \mathrm{~nm}$ and stained with uranyl acetate for $30 \mathrm{~min}$ and lead citrate for $15 \mathrm{~min}$ at room temperature, the cells were observed under a CM100 transmission electronic microscope at magnification, x6,600 (Philips Medical Systems B.V., Eindhoven, The Netherlands).

Terminal deoxynucleotidyltransferase-mediated dUTP nick-end labeling (TUNEL). DNA fragmentation was detected using the TUNEL technique with the In Situ Cell Apoptosis Detection kit, POD (Nanjing KeyGen Biotech Co., Ltd., Nanjing, China) performed according to the manufacturer's protocol. The cells grew prior on the glass slide were treated with COE at different concentrations for $24 \mathrm{~h}$. Next, $4 \%(\mathrm{w} / \mathrm{v})$ paraformaldehyde in PBS ( $\mathrm{pH} 7.4)$ was used for fixation of cells (30 $\mathrm{min}$ at room temperature) and rinsed twice with PBS. The fixed cells were then incubated in permeabilization solution $(0.1 \%$ Triton $\mathrm{X}-100$ in $0.1 \%$ sodium citrate) for $3 \mathrm{~min}$ at room temperature, and then the cells were incubated with blocking solution $\left(3 \% \mathrm{H}_{2} \mathrm{O}_{2}\right.$ in methanol) for $10 \mathrm{~min}$ at $25^{\circ} \mathrm{C}$ and rinsed with PBS. Subsequently, $50 \mu 1$ of reaction mixture containing TdT enzyme and nucleotide was added to the cells, and the cells were all incubated for $1 \mathrm{~h}$ at $37^{\circ} \mathrm{C}$ in the dark. The slides were washed with PBS and incubated with $50 \mu \mathrm{l}$ streptavidin-horseradish peroxidase working solution for $30 \mathrm{~min}$ at $37^{\circ} \mathrm{C}$ in the dark, and rinsed three times with PBS. Finally, the cells incubated with DAB were analyzed by light microscopy.

Western blot analysis. Expression levels of B-cell lymphoma 2 (BCL2; Epitomics, Burlingame, California, USA; cat. no. S0820; dilution, 1:1,000), Bcl-2-associated X 
A

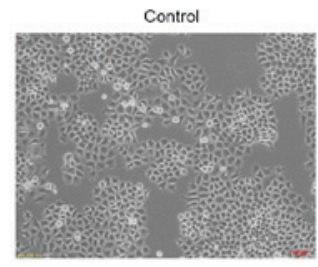

COE $40 \mathrm{mgl}$

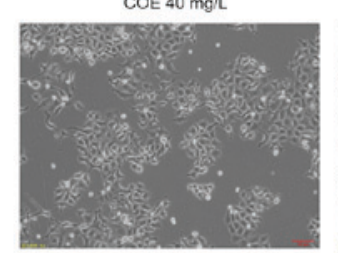

c

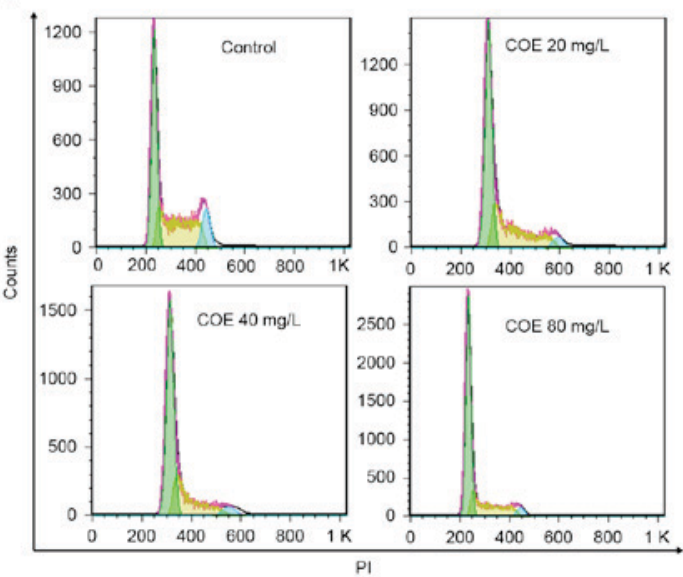

B
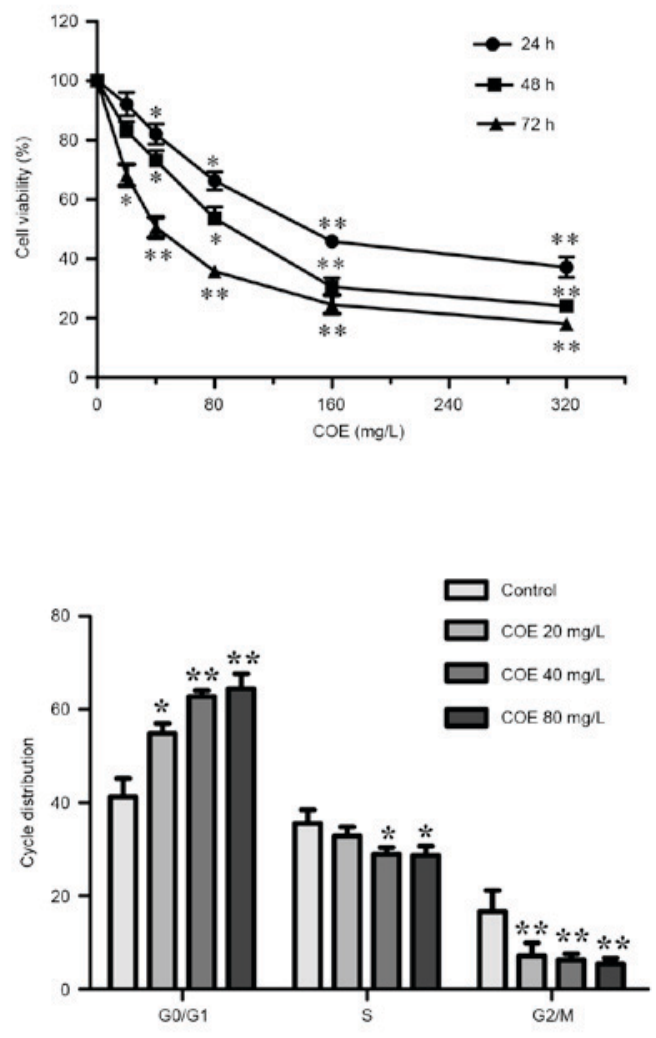

Figure 1. COE inhibited the proliferation of ESCC ECA-109 cells and induced cell cycle arrest. (A) ECA-109 cells were treated with COE at the indicated concentrations for 24,48 or $72 \mathrm{~h}$, followed by morphological observation. Scale bar, $100 \mu \mathrm{m}$. (B) The effect of COE on cell viability in ECA-109 cells. Cells were treated with $20,40,80,160$ or $320 \mathrm{mg} / \mathrm{l} \mathrm{COE}$ for 24,48 or $72 \mathrm{~h}$. Cell viability was measured by MTT assay. ${ }^{*} \mathrm{P}<0.05$ and ${ }^{* * *} \mathrm{P}<0.01 \mathrm{vs}$. control. (C) COE triggered $\mathrm{G}_{0} / \mathrm{G}_{1}$ cell cycle arrest. Cells were treated with COE at different concentrations $(20,40 \mathrm{or} 80 \mathrm{mg} / \mathrm{l})$ for $24 \mathrm{~h}$, followed by PI staining and fluorescence-activated cell sorting analysis of the cell cycle profile. Representative images (left) and results of statistical analysis (right) are presented. ${ }^{*} \mathrm{P}<0.05$ and ${ }^{* *} \mathrm{P}<0.01$ vs. control. COE, Celastrus orbiculatus extracts; ESCC, esophageal squamous carcinoma cells; PI, propidium iodide.

[Bax; Cell Signaling Technology (CST), Inc. Danvers, MA, USA; cat. no. 2772; dilution, 1:1,000], PI3K (CST; cat. no. 4249; dilution, 1:1,000), AKT (CST; cat. no. 4691; dilution, 1:1,000), phosphorylated (p)-AKT(Ser473) (CST; cat. no. 4058; dilution, 1:1,000), mTOR (CST; cat. no. 2983; dilution, 1:1,000), phosphorylated mTOR (Ser2448; CST; cat. no. 5536; dilution, $1: 1,000)$ in ECA-109 cells treated with $0,20,40$ or $80 \mathrm{mg} / \mathrm{l}$ COE were detected by western blot analysis. $\beta$-actin (CST; cat. no. 4970; dilution, 1:1,000) was used as a marker for cytosolic proteins. Lysate proteins were resolved by $10 \%$ SDS-PAGE and transferred onto nitrocellulose membranes (EMD Millipore, Billerica, MA, USA). Membranes were blocked in blocking buffer (5\% not-fat dry milk and 1\% Tween-20 in PBS) for $2 \mathrm{~h}$ at room temperature, and then incubated with appropriate primary antibodies in blocking buffer at $4^{\circ} \mathrm{C}$ overnight. Subsequently, the membranes were washed with TBS containing Tween-20 to remove the residual primary antibodies mentioned above, and incubated with horseradish peroxidase conjugated goat anti-rabbit immunoglobulin $\mathrm{G}$ secondary antibodies (Huaan Biotechnology company, Hangzhou, Zhejiang, China; cat. no. HA-1001-100; dilution, 1:2,000) for $2 \mathrm{~h}$ at room temperature. Enhanced chemiluminescence was used to detect signals, using the Super Signal West Pico Chemiluminescent Substrate (Thermo Fisher Scientific, Waltham, MA, USA) on a Molecular Imager Chemi Doc XRS System (Bio-Rad Laboratories, Inc., Hercules, CA, USA). The experiments were repeated 3 times. The bands from western blotting were quantified using Quantity One analysis software version 4.62 (Bio-Rad Laboratories, Inc.).

Inhibitor treatment. To investigate the effect of mTOR inhibition on cell growth, apoptosis and the cell cycle in ECA-109 cells further, confluent cell cultures were pretreated with $100 \mathrm{nM}$ rapamycin (Sigma-Aldrich, Merck KGaA; cat. no. R0395) for $1 \mathrm{~h}$ and then incubated in the presence or absence of COE (80 mg/l) for $24 \mathrm{~h}$. The cells were then subjected to the cell apoptosis assay, cell cycle analysis, evaluation of mitochondrial membrane depolarization, TUNEL assay, transmission electron microscopy and western blotting, as aforementioned.

Statistical analysis. Each experiment was repeated $\geq 3$ times. The experimental results were analyzed using SPSS 16.0 software (SPSS, Inc., Chicago, IL, USA). Data are expressed as the mean \pm standard deviation. Comparison between two groups was performed using the Student's t-test. Statistical comparisons of more than two groups were performed by one-way analysis of variance with Bonferroni's post hoc test. $\mathrm{P}<0.05$ was considered to indicate a statistically significant difference. 
A
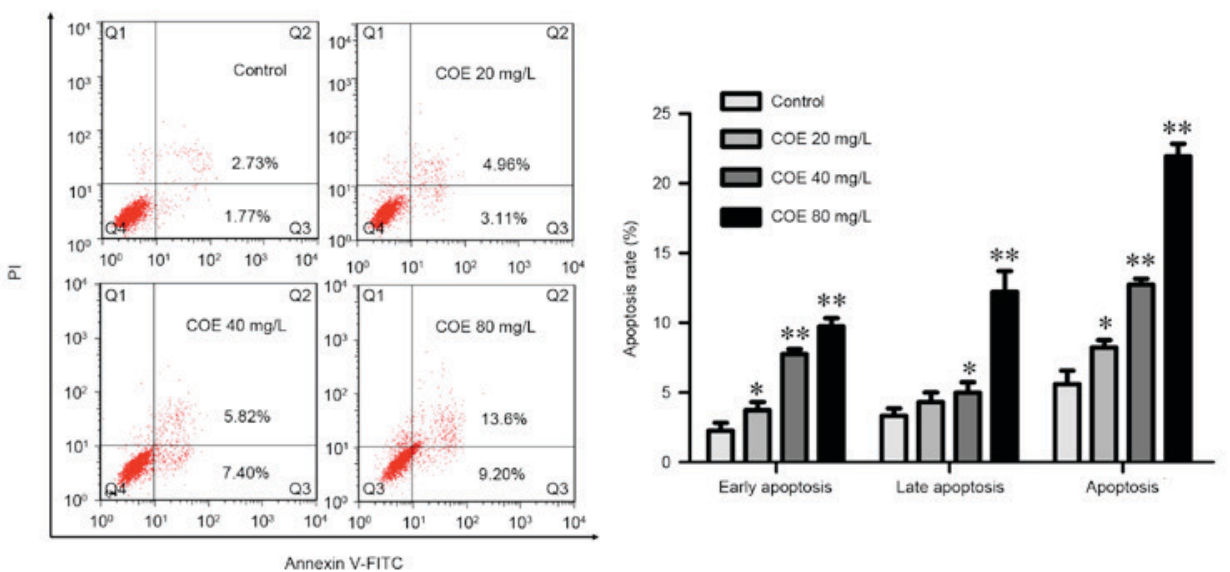

B
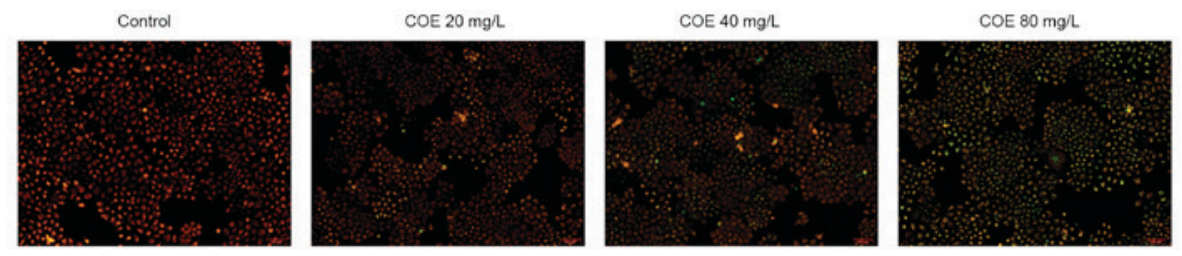

c
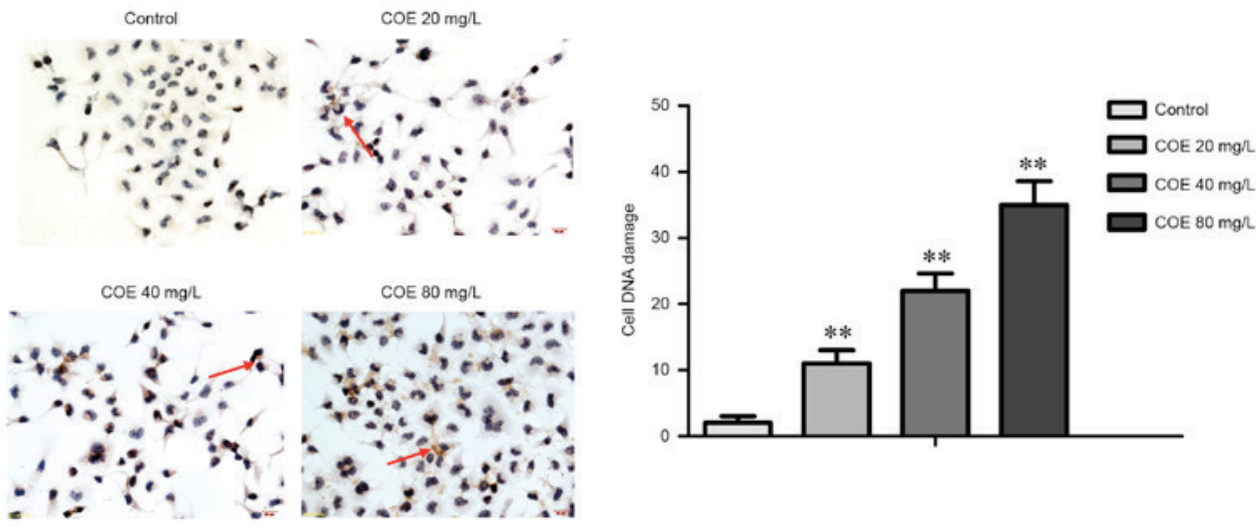

D

Control

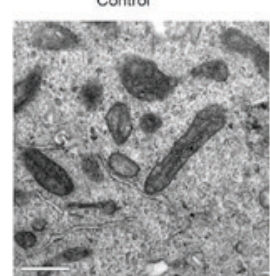

COE $20 \mathrm{mgl}$

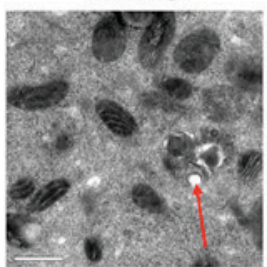

COE $40 \mathrm{mg} / \mathrm{L}$

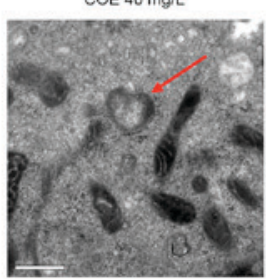

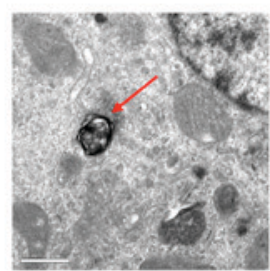

Figure 2. COE induced the apoptosis of ESCC. ECA-109 cells were treated with COE (20, $40 \mathrm{or} 80 \mathrm{mg} / \mathrm{l})$ for $24 \mathrm{~h}$. (A) Apoptosis was determined by Annexin V-FITC/PI double-staining analysis. Statistical results are presented in the right panels. ${ }^{*} \mathrm{P}<0.05$ and ${ }^{* *} \mathrm{P}<0.01$ vs. control. (B) The loss of mitochondrial membrane potential was detected using a JC-1 kit. Fluorescence microscopy (magnification, x100) was used to evaluate the levels of green monomeric vs. red polymeric JC-1 dye. Images are representative of three independent experiments. (C) DNA damage response was performed using a terminal deoxynucleotidyl transferase dUTP nick end labeling assay and quantified under a microscope (magnification, $\mathrm{x} 400$ ). Red arrow indicates representative DNA damage. Statistical results are presented in the right panels. ${ }^{~} \mathrm{P}<0.05$ and ${ }^{* *} \mathrm{P}<0.01$ vs. control. (D) Representative images obtained from transmission electron microscopy experiments. Double membrane apoptosis bodies (arrows) formed following COE treatment. Scale bar, $0.5 \mu \mathrm{m}$. COE, Celastrus orbiculatus extracts; ESCC, esophageal squamous carcinoma cells; FITC, fluorescein isothiocyanate; PI, propidium iodide.

The graphs were obtained using GraphPad Prism 5.0 software (GraphPad, Inc., La Jolla, CA, USA).

\section{Results}

COE inhibits the proliferation of ESCC. To assess the anticancer activity of COE on ESCC, the effect of COE on the proliferation of the ESCC ECA-109 cell line was investigated. Morphologically, with increasing concentrations of
COE, cells were increasingly shrunk and detached from the coverslip (Fig. 1A). As a result, the viability of cells decreased with $\mathrm{COE}$ treatment in a time- and dose-dependent manner, as assessed by MTT assay (Fig. 1B). The inhibitory effects on proliferation were not significant at 24 and $48 \mathrm{~h}$ in the $20 \mathrm{mg} / \mathrm{l}$ group.

COE induces $G_{0} / G_{1}$ cell cycle arrest in ESCC. The cell cycle assay demonstrated that $\mathrm{COE}$ produced a significant decrease 
A

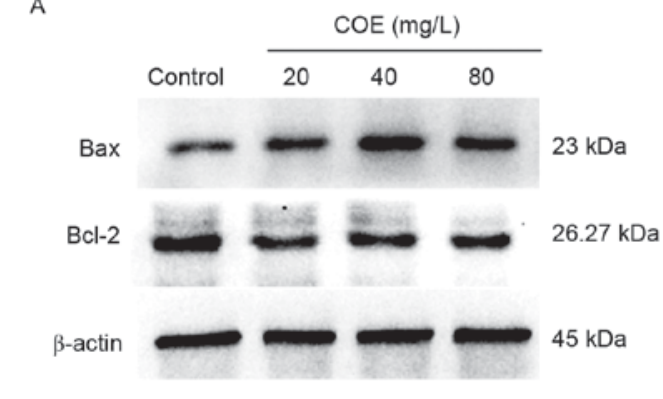

B
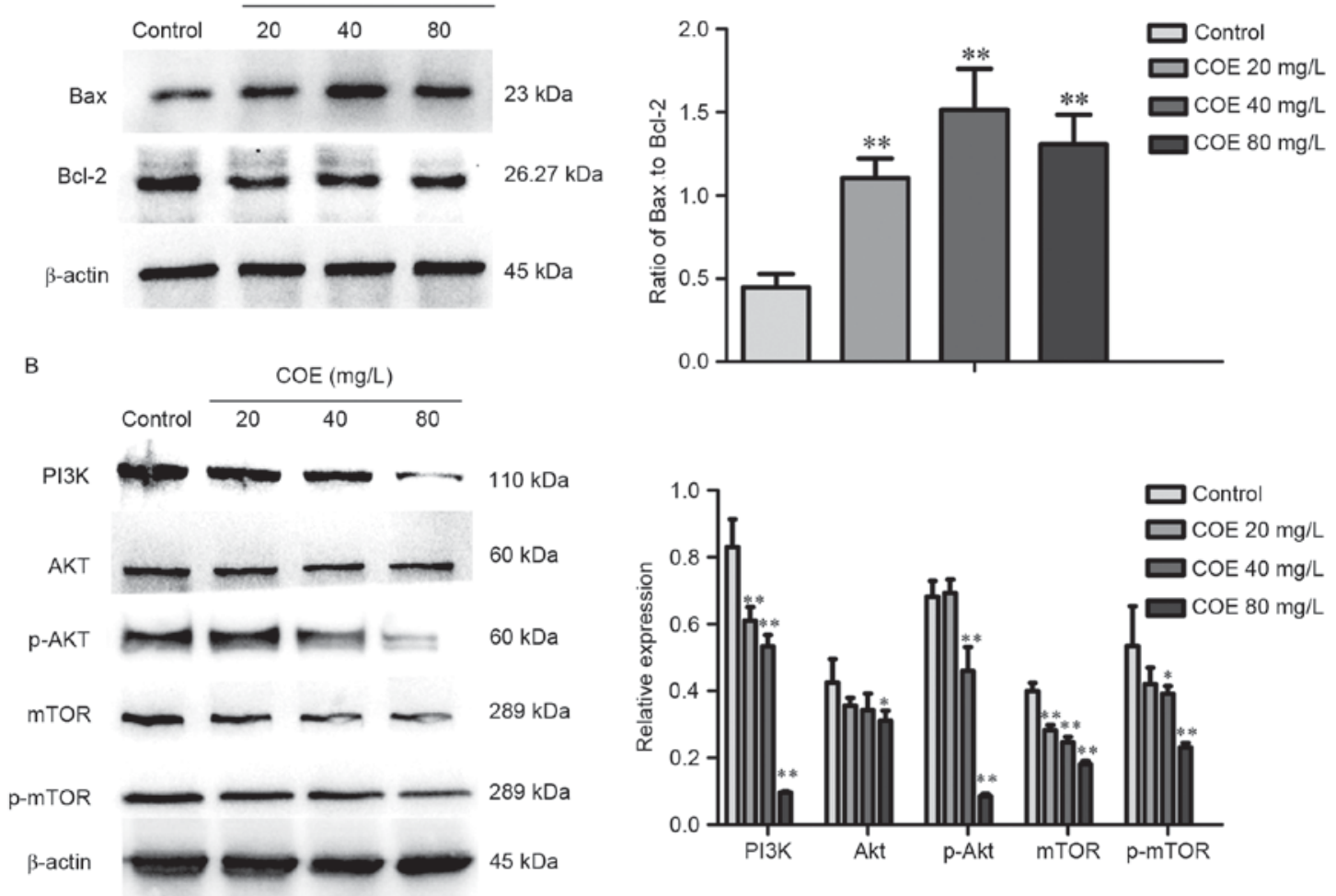

Figure 3. COE raised the ratio of Bax to Bcl-2 protein expression and blocked the PI3K/Akt/mTOR signaling pathways. ECA-109 cells were treated with COE $(20,40$ or $80 \mathrm{mg} / \mathrm{l})$ for $24 \mathrm{~h}$. (A) COE increased the ratio of Bax to Bcl-2 protein expression. (B) COE blocked the PI3K/Akt/mTOR signaling pathways. "P $<0.05$ and ${ }^{* *} \mathrm{P}<0.01$ vs. control. COE, Celastrus orbiculatus extracts; Bcl-2, B-cell lymphoma 2; Bax, Bcl-associated X; PI3K, phosphoinositide-3 kinase; Akt, protein kinase B; mTOR, mechanistic target of rapamycin.

in the number of cells in the $\mathrm{G}_{2} / \mathrm{M}$ phase, and a significant accumulation in the number of cells in the $\mathrm{G}_{0} / \mathrm{G}_{1}$ phase. These findings clearly demonstrated that $\mathrm{COE}$ triggered $\mathrm{G}_{0} / \mathrm{G}_{1}$ cell cycle arrest in ECA-109 cells in a dose-dependent manner (Fig. 1C).

COE induces apoptosis in ESCC. Next, whether apoptosis was responsible for the anticancer activity of COE was assessed. The results demonstrated that $\mathrm{COE}$ treatment led to the significant accumulation of cells in early-(Annexin $\left.\mathrm{V}^{+} / \mathrm{PI}\right)$ and late-stage (Annexin $\mathrm{V}^{+} / \mathrm{PI}^{+}$) apoptosis in a dose-dependent manner (Fig. 2A). The proportion of cells in early apoptosis significantly increased when COE was added, whereas the percentage of late apoptosis cells treated with $20 \mathrm{mg} / \mathrm{l} \mathrm{COE}$ did not significantly change.

$\mathrm{COE}$ induced the loss of mitochondrial membrane potential (Fig. 2B), a classical marker of the activation of intrinsic apoptosis, which indicated that $\mathrm{COE}$ triggered mitochondrial apoptosis. This was indicated by the transition of JC-1 fluorescence from red to green gradually with the increasing concentration gradient.

COE induces DNA damage and increases the amount of apoptotic bodies in ESCC. To determine whether $\mathrm{COE}$ induces the DNA damage response, a TUNEL assay was performed to detect apoptotic nuclei in ECA-109 cells (Fig. 2C). The TUNEL staining revealed gradual and significant increases in the rate of apoptosis in the groups treated with 20,40 , and $80 \mathrm{mg} / \mathrm{l} \mathrm{COE}$.
To verify apoptosis, transmission electron microscopy was used to observe organelles in ECA-109 cells treated with COE (Fig. 2D). The results revealed that untreated cells possessed normal mitochondria and cytoplasm, whereas COE-treated cells exhibited the appearance of apoptotic bodies of various sizes. Swollen and transparent mitochondria were also observed by electron microscopy, which occurred in a DOE dose-dependent manner.

COE inhibits the PI3K/Akt/mTOR signaling pathway in $E S C C$. Western blot analysis demonstrated that treatment with $\mathrm{COE}$ significantly increased the ratio of $\mathrm{Bax}$ to $\mathrm{Bcl}-2$ protein, whereby the effect was larger in the $40 \mathrm{mg} / \mathrm{l}$ compared with $80 \mathrm{mg} / \mathrm{l}$ treatment group (Fig. 3A). As presented in Fig. 3B, levels of PI3K, phosphorylated Akt, mTOR, phosphorylated mTOR were significantly lower in groups treated with COE compared with the control group, with no significant changes in Akt expression overall.

COE inhibits proliferation, and induces cell cycle arrest and apoptosis through PI3K/Akt/mTOR signaling pathways. The combined treatment of rapamycin and COE significantly induced cell cycle arrest (Fig. 4A), and apoptosis (Fig. 4B) compared with treatment with $\mathrm{COE}$ alone. In addition, the effects of combination treatment on the decrease of mitochondrial membrane potential were significantly more evident compared with treatment with COE alone (Fig. 5A). Furthermore, apoptotic bodies induced by combination treatment were markedly more evident compared with $\mathrm{COE}$ alone 
A

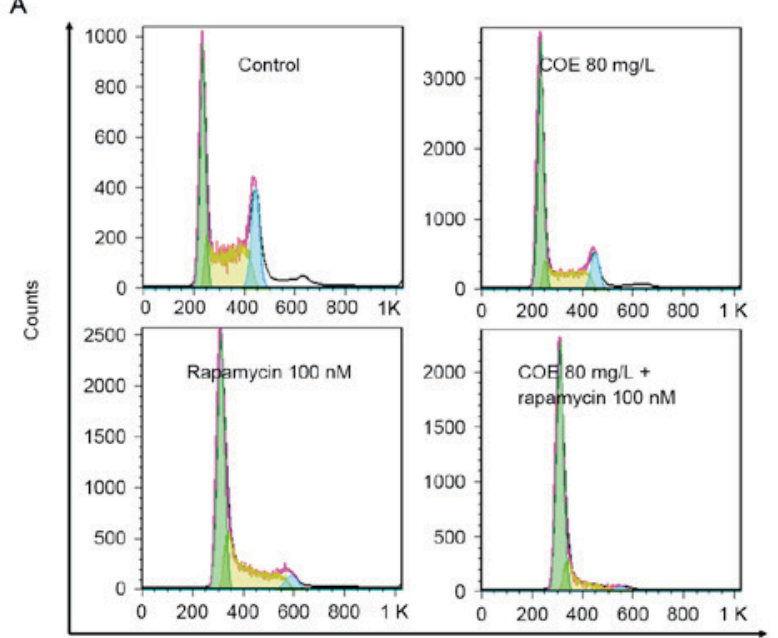

PI

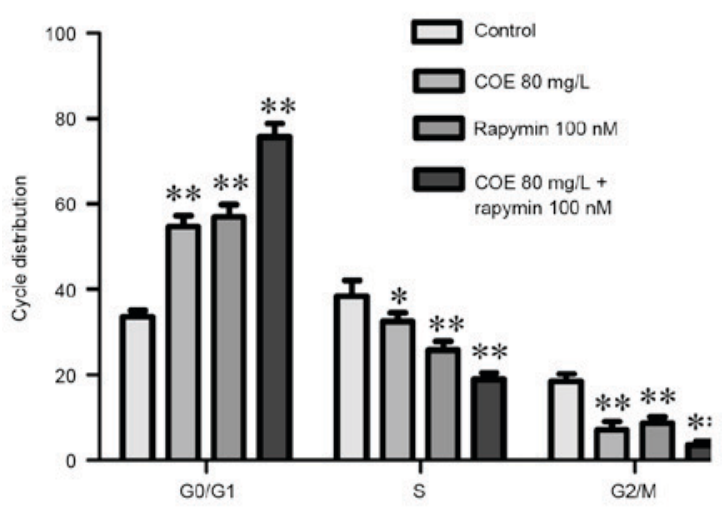

C
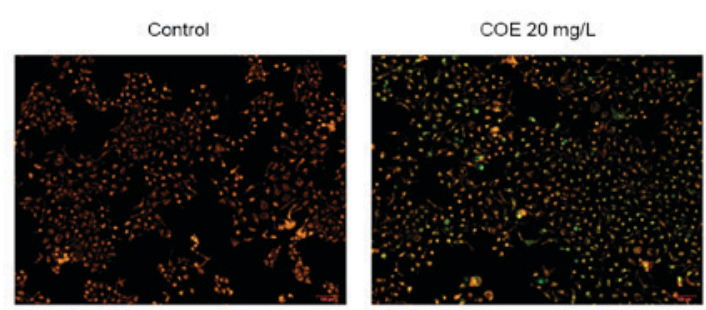

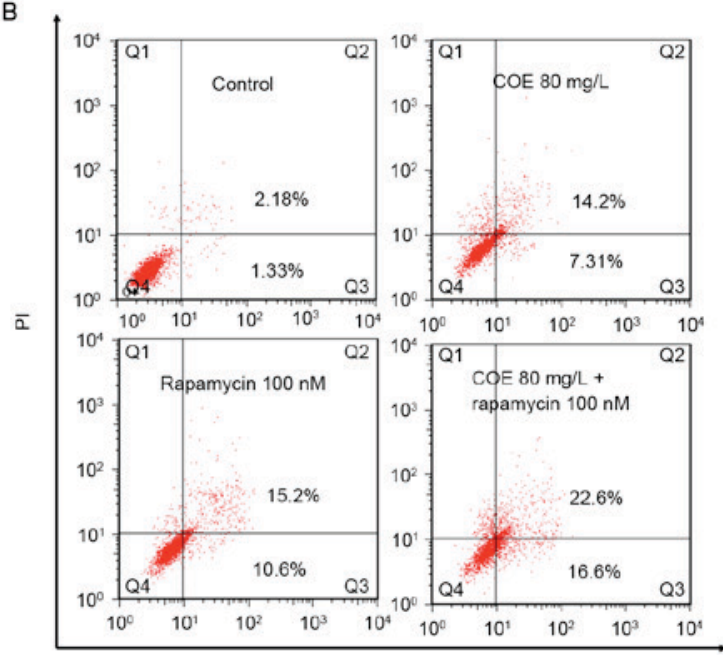

Annexin V-FITC
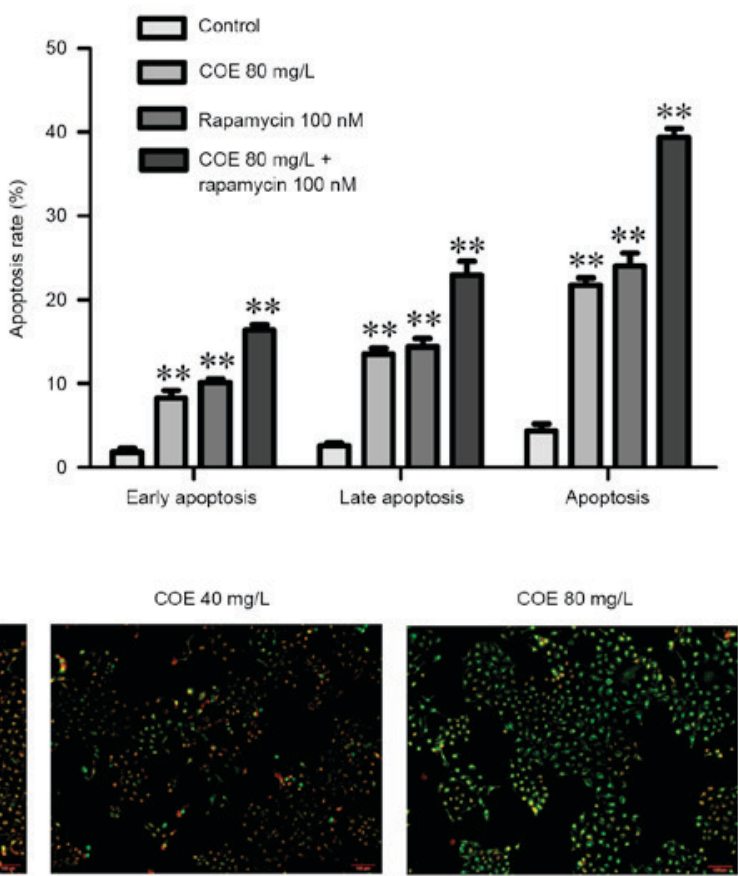

Figure 4. Combination treatment of rapamycin and COE could further induced cell cycle arrest and apoptosis. ECA-109 cells were treated with the solution of different ingredients (COE $80 \mathrm{mg} / 1$, rapamycin $100 \mathrm{nM}$ ) for $24 \mathrm{~h}$. (A) The combination treatment of rapamycin and COE further induced cell cycle arrest by triggering $\mathrm{G}_{0} / \mathrm{G}_{1}$ cell cycle arrest. "P<0.05 and ${ }^{* *} \mathrm{P}<0.01$ vs. control. (B) Assessment of confluent cell cultures found that the combination treatment further induced apoptosis, as assessed by Annexin V-FITC/PI double-staining analysis. ${ }^{*} \mathrm{P}<0.05$ and ${ }^{* * *} \mathrm{P}<0.01$ vs. control. (C) The combination treatment further reduced the mitochondrial membrane potential, as assessed using the JC-1 kit. Images were obtained from the Fluorescence Inversion Microscope system (magnification, x100). COE, Celastrus orbiculatus extracts; FITC, fluorescein isothiocyanate; PI, propidium iodide.

(Fig. 5B). Western blot analysis indicated that the combination treatment significantly enhanced the observed changes that occurred following treatment with $\mathrm{COE}$ or rapamycin alone, including changes to the $\mathrm{Bax} / \mathrm{Bcl}-2$ ratio (Fig. $6 \mathrm{~A}$ ), and $\mathrm{PI} 3 \mathrm{~K}$, Akt, p-Akt, mTOR and p-mTOR protein expression levels (Fig. 6B).

\section{Discussion}

Traditional Chinese herbs have been widely used in the treatment of cancer in Asia (23). The antitumor effects of traditional Chinese medicine have been further studied, including their antiproliferative, anti-angiogenic and pro-apoptotic effects $(26,27)$. COE is extracted from the plant of Celastrus orbiculatus, which is widely used in traditional Chinese medicine. Previous studies had reported that treatment with COE exerts an antitumor effect on several types of tumors in a cell-type-dependent manner (16-24). COE exhibits distinct antitumor activities, including the inhibition of cell proliferation, induction of cell apoptosis and inhibition of angiogenesis (16-24). Qian et al (16) reported that COE inhibited tumor angiogenesis by modulating the vascular endothelial growth factor signaling pathway. Zhu et al (22-24) reported that COE suppressed tumor growth factor- $\beta 1$-induced epithelial-mesenchymal transition by inhibiting HSP27 and the tumor necrosis factor- $\alpha$-induced nuclear factor- $\kappa \mathrm{B} /$ Snail signaling pathway in human gastric adenocarcinoma. Therefore, COE may be a novel therapeutic agent 
A

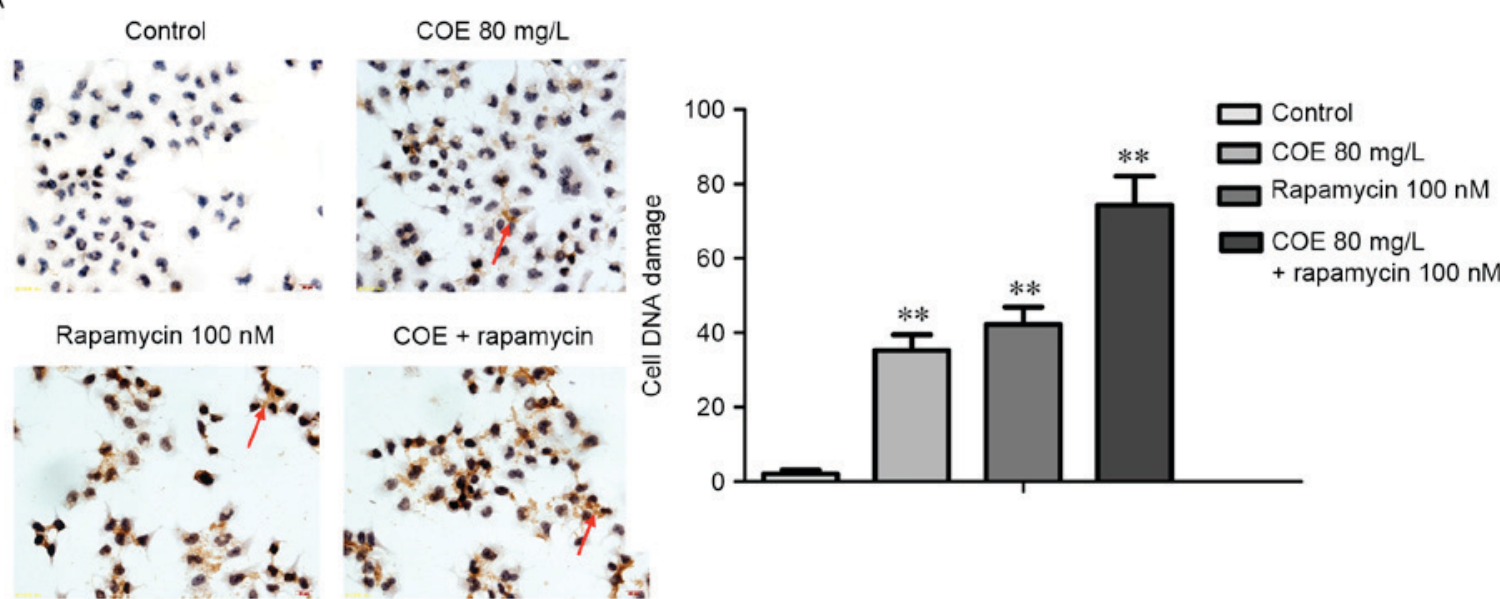

B

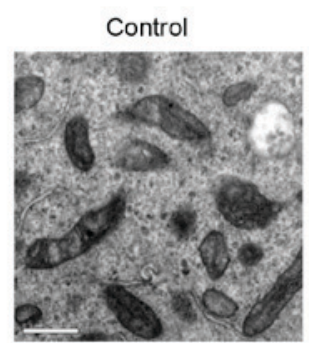

COE $80 \mathrm{mg} / \mathrm{L}$

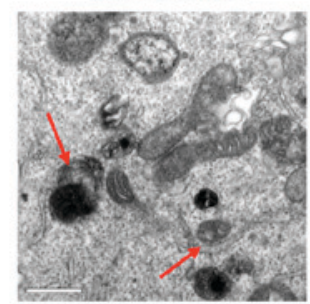

Rapamycin $100 \mathrm{nM}$

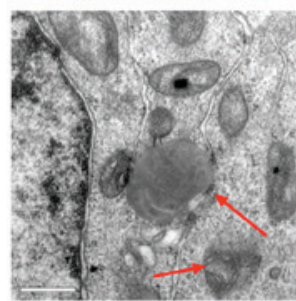

$\mathrm{COE}+$ rapamycin

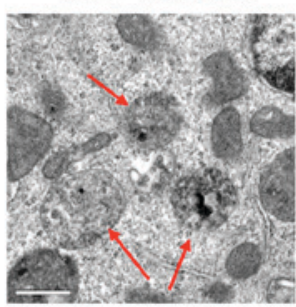

Figure 5. Combination treatment of rapamycin and COE could further give the raise to the DNA damage and increase the amount of apoptosis bodies. ECA-109 cells were treated with the solution of different ingredients (COE $80 \mathrm{mg} / 1$, rapamycin $100 \mathrm{nM}$ ) for $24 \mathrm{~h}$. (A) DNA damage response was performed with terminal deoxynucleotidyl transferase dUTP nick end labeling assay and quantified under a microscope (magnification, $\mathrm{x} 400$ ). The red arrow indicates the representative DNA damage. ${ }^{* *} \mathrm{P}<0.01$ vs. control. (B) The apoptotic bodies (arrows) were more numerous with combination treatment, as assessed using transmission electron microscopy. Scale bar, $0.5 \mu \mathrm{m}$. COE, Celastrus orbiculatus extracts.
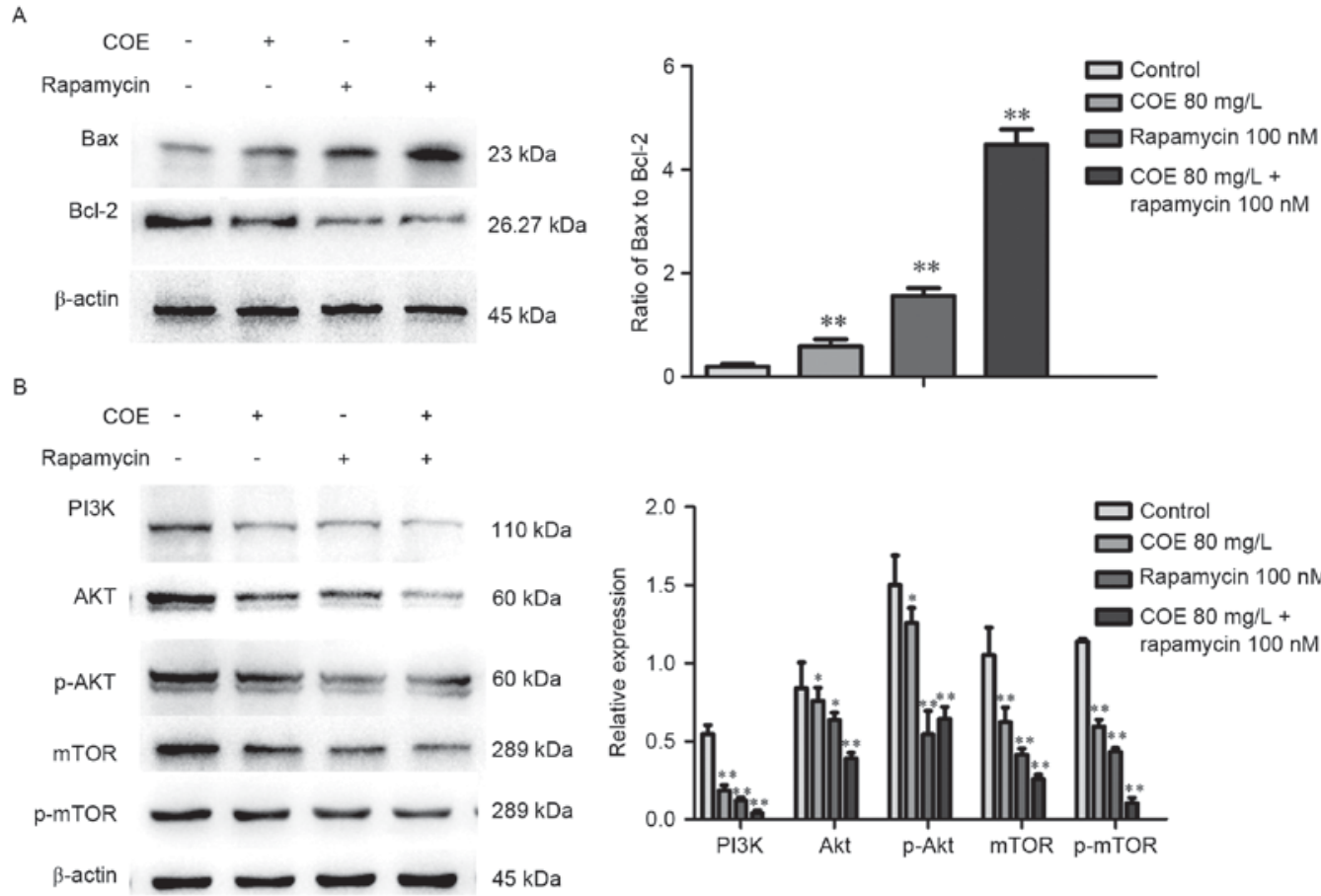

Figure 6. Combination treatment of rapamycin and COE could further raise the ratio of Bax to Bcl-2 protein and blocked the PI3K/Akt/mTOR signaling pathways. ECA-109 cells were treated with $80 \mathrm{mg} / \mathrm{l} \mathrm{COE}$ and $100 \mathrm{nM}$ rapamycin for $24 \mathrm{~h}$. (A) The combination treatment increased the ratio of Bax to Bcl-2 protein expression above that elicited with treatment of either alone. " $\mathrm{P}<0.05$ and ${ }^{* *} \mathrm{P}<0.01$ vs. control. (B) The combination treatment increased blocked activation of the PI3K/Akt/mTOR signaling pathways above that blocked by treatment of either alone. ${ }^{*} \mathrm{P}<0.05$ and ${ }^{* * *} \mathrm{P}<0.01$ vs. control. COE, Celastrus orbiculatus extracts; Bcl-2, B-cell lymphoma 2; Bax, Bcl-associated X; PI3K, phosphoinositide-3 kinase; p-Akt, phosphorylated protein kinase B; mTOR, mechanistic target of rapamycin. 
targeted at digestive tract cancer cells. However, the antitumor effects and the associated mechanisms of COE treatment for ESC remain undefined.

The present study assessed and validated the efficacy of treatment with $\mathrm{COE}$ alone and in combination with rapamycin in ESCC in vitro. COE induced cells change from normal adherence to a shrunk and floated status with increasing concentrations of COE. An MTT assay revealed that COE decreased the viability of cells in a time- and dose-dependent manner. To exclude any cytotoxic effect, a low-toxicity concentration was chosen $(<80 \mathrm{mg} / \mathrm{l})$ of $\mathrm{COE}$ for further experiments. The cell cycle assay indicated that COE may induce cell cycle arrest by triggering induction of the $G_{0} / G_{1}$ phase. COE induced early and late apoptosis in ECA-109 cells at 40 , and $80 \mathrm{mg} / \mathrm{l}$. The mitochondrial membrane potential assay also demonstrated the action of COE on mitochondria, which are central to the process of apoptosis. Furthermore, the TUNEL assay revealed that COE caused DNA damage in a dose-dependent manner. To observe the organelles within ECA-109 cells treated with COE further, transmission electron microscopy was used, revealing that mitochondria were swollen and transparent, and apoptotic bodies appeared in a dose-dependent manner. To determine the effects of $\mathrm{COE}$ at the molecular level, the protein expression of Bax and Bcl-2 were detected, whereby a decrease in the ratio of Bcl-2 to Bax expression is known to be associated with apoptosis $(28,29)$. The results revealed that COE increased the $\mathrm{BAX} / \mathrm{Bcl}-2$ ratio, and the effect of $40 \mathrm{mg} / 1$ was preferable to $80 \mathrm{mg} / \mathrm{l}$. Previous studies have reported that COE promoted apoptosis in human hepatocellular carcinoma cells via inhibition of the AKT signaling pathway and inhibited human colorectal carcinoma cell metastasis via suppression of the mTOR signaling pathway (16-20). On the basis of these previous results, the present study assessed the expression of the PI3K/AKT/mTOR signaling pathway. It was demonstrated that the levels of PI3K, p-AKT, mTOR and p-mTOR decreased significantly, while the expression of AKT did not change following $\mathrm{COE}$ treatment. In addition, the combined treatment of rapamycin and COE further inhibited cellular proliferation, and induced cell cycle arrest and apoptosis.

In conclusion, the present study revealed that COE treatment inhibits proliferation and induces apoptosis in ECA-109 cells by triggering $G_{0} / G_{1}$ cell cycle arrest and DNA damage. Furthermore, the effects of COE combined with rapamycin are superior to treatment with either alone. These results suggest that the possible mechanism of COE on ESCC involves the $\mathrm{PI} 3 \mathrm{~K} / \mathrm{AKT} / \mathrm{mTOR}$ signal pathway. The findings of the present study extend the understanding of COE and suggest that it may be considered as a treatment option for ESCC, alone or in combination with other drugs. However, all of the experiments in the present study were performed in vitro, and further study will be performed to evaluate the efficacy of COE on cell growth and apoptosis of ESCC in vivo.

\section{Acknowledgements}

The present study was supported by the National Natural Science Foundation of China (grant nos. 81773944 and 81573656) and the Natural Science Foundation of Jiangsu Province (grant no. BK20171290 and BK20170516).

\section{References}

1. Zhang Y: Epidemiology of esophageal cancer. World J Gastroenterol 19: 5598-5606, 2013.

2. Roshandel G, Majdzadeh R, Keshtkar A, Aramesh K, Sedaghat SM and Semnani S: Healthcare utilization in patients with esophageal cancer in a high risk area in northeast of Iran. Asian Pac J Cancer Prev 12: 2437-2442, 2011.

3. Maleki I, Shekarriz R, Nosrati A and Orang E: Simultaneous esophageal squamous cell carcinoma and adenocarcinoma: A case report. Middle East J Dig Dis 7: 257-260, 2015.

4. Roshandel G, Boreiri M, Sadjadi A and Malekzadeh R: A diversity of cancer incidence and mortality in West Asian populations. Ann Glob Health 80: 346-357, 2014.

5. Ferlay J, Soerjomataram I, Dikshit R, Eser S, Mathers C, Rebelo M, Parkin DM, Forman D and Bray F: Cancer incidence and mortality worldwide: Sources, methods and major patterns in GLOBOCAN 2012. Int J Cancer 136, E359-E386, 2015.

6. Lu CL, Lang HC, Luo JC, Liu CC, Lin HC, Chang FY and Lee SD: Increasing trend of the incidence of esophageal squamous cell carcinoma, but not adenocarcinoma, in Taiwan. Cancer Causes Control 21, 269-274, 2010.

7. He YT, Hou J, Chen ZF, Qiao CY, Song GH, Meng FS, Jin HX and Chen C: Trends in incidence of esophageal and gastric cardia cancer in high-risk areas in China. Eur J Cancer Prev 17: 71-76, 2008.

8. Porta C, Paglino C and Mosca A: Targeting PI3K/Akt/mTOR Signaling in Cancer. Front Oncol 14: 64, 2014.

9. Lee JJ, Loh K and Yap YS: PI3K/Akt/mTOR inhibitors in breast cancer. Cancer Biol Med 12: 342-354, 2015.

10. Hu A, Sun M, Yan D and Chen K: Clinical significance of mTOR and eIF4E expression in invasive ductalcarcinoma. Tumori 100: 541-546, 2014.

11. Liu NB, Zhang JH, Liu YF, Li J, Zhang ZZ, Li JW, Liu WY, Huang C, Shen T, Gu CW, et al: High DEPTOR expression correlates with poor prognosis in patients with esophageal squamous cell carcinoma. Onco Targets Ther 8: 3449-3455, 2015.

12. Burris HA III: Overcoming acquired resistance to anticancer therapy: Focus on the PI3K/AKT/mTOR pathway. Cancer Chemother Pharmacol 71: 829-842, 2013.

13. Wang M: Research progress of a Chinese herb Celastrus on antitumor effect. J Chinese Medicine 25: 1055-1057, 2010 (In Chinese).

14. Li JJ, Yang J, Lu F, Qi YT, Liu YQ, Sun Y and Wang Q: Chemical constituents from the stems of Celastrus orbiculatus. Chin J Nat Med 10: 279-283, 2012 (In Chinese).

15. Zan K, Chen X, Wang Q and Cao L: Chemical constituents in stem of Celastrus orbiculatus. Chin Tradit Herbal Drugs 38: 1455, 2007 (In Chinese).

16. Qian YY, Zhang H, Hou Y, Yuan L, Li GQ, Guo SY, Hisamits T and Liu YQ: Celastrus orbiculatus extract inhibits tumor angiogenesis by targeting vascular endothelial growth factor signaling pathway and shows potent antitumor activity in hepatocarcinomas in vitro and in vivo. Chin J Integr Med 18: 752-760, 2012.

17. Wang $M$, Zhang $X$, Xiong $X$, Yang Z, Sun Y, Yang Z, Hoffman RM and Liu Y: Efficacy of the Chinese traditional medicinal herb Celastrus orbiculatus Thunb on human hepatocellular carcinoma in an orthothopic fluorescent nude mouse model. Anticancer Res $32: 1213-1220,2012$.

18. Zhang H, Qian Y, Liu Y, Li G, Cui P, Zhu Y, Ma H, Ji X, Guo S and Tadashi H: Celastrus orbiculatus extract induces mitochondrial-mediated apoptosis in human hepatocellular carcinoma cells. J Tradit Chin Med 32: 621-626, 2012.

19. Qian YY and Liu YQ: Inhibition of Celastrus orbiculatus extracts on VEGF expression in hepatoma cells of mice. Chinese Herbal Med 2: 72-76, 2010.

20. Hui MA, Yayun Q, Hua Z, Xue J, Yaodong Z, Pingfang C and Yanqing L: Celastrus orbiculatus extract could inhibit human colorectal carcinoma HT-29 cells metastasis via suppression of the mTOR signaling pathway. Life Sci J 10: 1704-1710, 2013.

21. Li G, Liu D, Guo S, Sunagawa M, Hisamitsu T and Liu Y: Anti-invasive effects of Celastrus orbiculatus extract on interleukin-1 betaand tumour necrosis factor-alpha combination-stimulated fibroblast-likesynoviocytes. BMC Complement Altern Med 14, 62, 2014.

22. Zhu Y, Liu Y, Qian Y, Dai X, Yang L, Chen J, Guo S and Hisamitsu T: Antimetastatic effects of Celastrus orbiculatus on human Gastricadenocarcinoma by inhibiting epithelial-mesenchymal transition and NF- $x \mathrm{~B} /$ snail signaling pathway. Integr Cancer Ther 14: 271-281, 2015. 
23. Zhu YD, Liu YQ, Qian YY, Zhang H, Li GQ and Yang L: Extracts of Celastrus orbiculatus exhibit anti-proliferative and anti-invasiveeffects on human gastric adenocarcinoma cells. Chin J Integr Med: Nov 10, 2014 (Epub ahead of print).

24. Zhu Y, Liu Y, Qian Y, Yang L, Chen J, Guo S and Hisamitsu T: Research on the efficacy of Celastrus orbiculatus in suppressing TGF- $\beta 1$-induced epithelial-mesenchymal transition by inhibiting HSP27 and TNF- $\alpha$-induced NF- $\mathrm{B} /$ Snail signaling pathway in human gastric adenocarcinoma. BMC Complement Altern Med 14: 433, 2014

25. Tao W, Luo X, Cui B, Liang D, Wang C, Duan Y, Li X, Zhou S, Zhao M and Li Y: Practice of traditional Chinese medicine for psycho-behavioral intervention improves quality of life in cancer patients: A systematic review and meta-analysis. Oncotarget 6 : 39725-39739, 2015.

26. $\mathrm{Xu} \mathrm{H,} \mathrm{Zhao} X$, Liu $X$, Xu $P$, Zhang $K$ and Lin $X$ : Antitumor effects of traditional Chinese medicine targeting the cellularapoptotic pathway. Drug Des Devel Ther 9: 2735-2744, 2015.
27. Zhang YS, Shen Q and Li J: Traditional Chinese medicine targeting apoptotic mechanisms for esophageal cancer therapy. Acta Pharmacol Sin 37: 295-302, 2016.

28. Liu Z, Ding Y, Ye N, Wild C, Chen H and Zhou J: Direct activation of bax protein for cancer therapy. Med Res Rev 36: 313-341, 2016.

29. Thomas S, Quinn BA, Das SK, Dash R, Emdad L, Dasgupta S, Wang XY, Dent P, Reed JC, Pellecchia M, et al: Targeting the Bcl-2 family for cancer therapy. Expert Opin Ther Targets 17: $61-75,2013$

(i) $(9)$ This work is licensed under a Creative Commons Attribution-NonCommercial-NoDerivatives 4.0 International (CC BY-NC-ND 4.0) License. 